\title{
PENGARUH PEMBERIAN REWARD DAN CONSEQUENCES TERHADAP MOTIVASI BELAJAR MURID KELAS IV DALAM KERANGKA PENDIDIKAN KRISTEN
}

\author{
Dian Kusuma Widyastuti", Iman Subekti \\ Program Studi Pendidikan Guru Sekolah Dasar, Universitas Kristen Petra \\ Jl. Siwalankerto 121-131, Surabaya \\ E-mail: *diankusuma2604@gmail.com; ${ }^{2}$ imansubekti@ petra.ac.id \\ *Penulis korespondensi
}

\begin{abstract}
ABSTRAK
Banyak guru yang kurang menyadari akan arti pentingnya pemberian reward atau penghargaan dan consequences atau konsekuensi kepada murid-muridnya. Guru hanya terfokus pada pemberian nilai atau skor ketika murid telah menyelesaikan penilaiannya. Pemberian reward dan consequences memiliki peranan yang sangat penting dalam proses pembelajaran para murid sehingga alangkah baiknya jika pemberian reward dan consequences dilakukan oleh guru dalam setiap interaksi selama berada di sekolah khususnya pada saat pembelajaran di kelas.

Penelitian ini berfokus pada pemberian reward dan consequences dalam kerangka Pendidikan Kristen. Penelitian ini bertujuan untuk mengetahui pengaruh pemberian reward terhadap motivasi belajar, pemberian consequences terhadap motivasi belajar, serta pengaruh pemberian reward dan consequences secara bersamaan terhadap motivasi belajar dan seberapa besar pengaruhnya.

Hasil analisis data berdasarkan uji pengaruh menunjukkan adanya pengaruh pada pemberian reward terhadap motivasi belajar murid yaitu sebesar $21,2 \%$. Pengaruh pemberian consequences terhadap motivasi belajar murid sebesar $23,9 \%$. Sedangkan ketika pemberian reward dan consequences diberikan secara bersama-sama kepada murid maka pengaruhnya terhadap motivasi belajar murid sebesar 30,3\% dengan persamaan regresinya $\mathrm{Y}=21,737+0,272 \mathrm{X} 1+0,345 \mathrm{X} 2$ yang berarti bahwa jika reward dan consequences naik satu-satuan maka masing-masing naik sebesar 0,272 dan 0,345 . Kesimpulan penelitian ini adalah pemberian reward dan consequences secara bersama-sama berpengaruh terhadap motivasi belajar murid dan pengaruhnya lebih besar.
\end{abstract}

Kata kunci: Consequences, Motivasi Belajar, Reward.

\footnotetext{
ABSTRACT

Many teachers do not realize the importance of giving rewards and consequences to their students. Teachers only focus on giving grades or scores when students have completed their assessment. Giving rewards and consequences has a very important role in the learning process of students. Therefore, it would be better if the teacher gives rewards and consequences in every interaction while in school, especially when learning in class.
} 
This study focuses on the provision of rewards and consequences in the framework of Christian education. This study aims to determine the effect of giving rewards on learning motivation, the effect of giving consequences towards learning motivation, and the effect of both simultaneously on learning motivation and the amount of influence it affects the students.

The results of the data analysis based on the influence test showed that there was an effect on the provision of rewards on student learning motivation which was 21.2\%. The effect of giving the consequences on student learning motivation is $23.9 \%$. Whereas when the reward and consequences are given together, the effect on student learning motivation is $30.3 \%$ with the regression equation $Y=21.737+0.272 X 1+0.345 X 2$, which means that if the reward and consequences increase by one unit, then increased by 0.272 and 0.345 , respectively. The conclusion of this study is that the giving of rewards and consequences simultaneously affects students' learning motivation and has a greater effect.

Keywords: Consequences, Motivation to Learn, Rewards.

\section{PENDAHULUAN}

Pendidikan merupakan sebuah kebutuhan pokok dalam menunjang kehidupan manusia. Setiap manusia berhak dan wajib mengikuti pendidikan, agar dapat mengembangkan semua aspek pengetahuan, keterampilan, perkembangan, dan kepribadian dirinya. Dalam dunia pendidikan, peran serta seorang guru memang sangat diperlukan. Guru adalah penanggung jawab dalam kegiatan pembelajaran. Hingga saat ini, peran seorang guru tidak dapat digantikan oleh apapun. Dengan demikian guru perlu menciptakan suatu proses pembelajaran yang dapat meningkatkan motivasi belajar murid,sehingga murid mampu belajar dengan efektif.

Dalam Undang-undang RI No. 20 Tahun 2003 tentang Sistem Pendidikan Nasional menyatakan bahwa:

"Pendidikan adalah usaha
sadar dan terencana untuk
mewujudkan suasana belajar
dan proses pembelajaran agar
peserta didik secara aktif
mengembangkan potensi
dirinya untuk memiliki
kekuatan spiritual keagamaan,

pengendalian diri, kepribadian, kecerdasan, akhlak mulia, serta keterampilan yang diperlukan dirinya, masyarakat, bangsa, dan negara."

Salah satu tugas yang harus dilakukan oleh guru dalam proses pembelajaran adalah memberikan motivasi kepada murid. Motivasi belajar merupakan salah satu dari jenis motivasi yang dimiliki oleh seseorang, sehingga setiap murid diharapkan mampu mengembangkan motivasi belajar yang ada dalam dirinya. Manfaat motivasi belajar salah satunya adalah sebagai dasar dalam melakukan kegiatan belajar. Motivasi murid dapat timbul dari dalam diri (motivasi intrinsik) dan dapat timbul dari luar diri (motivasi ekstrinsik).

Pada realitanya saat ini, murid yang dapat menimbulkan motivasi belajar dari dalam dirinya sendiri masih jarang. Hal tersebut terjadi karena kesadaran murid untuk berprestasi masih terbatas. Salah satu cara untuk meningkatkan motivasi belajar dari luar diri murid adalah dengan cara memberikan sebuah penghargaan.

Hingga saat ini, masih ada beberapa sekolah yang belum sepenuhnya menerapkan pemberian reward atau penghargaan dan punishment atau hukuman dalam pembelajaran di kelas (Ikranagara, 2016). Seringkali guru memilih untuk memberikan punishment kepada murid. Sebenarnya dalam pemberian hukuman tersebut, bisa 
jadi murid menjadi trauma dan menjadi tidak memiliki motivasi dalam belajar. Alangkah baiknya jika guru menggantikan punishment tersebut dengan consequences atau konsekuensi.

Murid yang mendapatkan reward dan consequences merupakan individu yang memiliki kemampuan atau karakter yang berbeda dan patut untuk dihargai. Reward diberikan kepada murid yang memiliki kemampuan positif. Sedangkan consequences diberikan kepada murid yang memiliki kemampuan kurang positif.

Guru dapat memberikan reward dan consequences dengan beberapa cara yaitu dengan cara verbal dan nonverbal. Reward dan consequences merupakan salah satu yang bisa dilakukan untuk membentuk motivasi belajar murid. Guru lebih terfokus kepada ingin memperbaiki perilaku murid yang salah dengan memberikan consequences. Sedangkan murid yang berperilaku baik dibiarkan saja, tidak diperhatikan, dan tidak diberikan reward. Guru menganggap bahwa berperilaku baik adalah suatu hal yang sudah semestinya bisa dilakukan murid (Anggraini \& Siswanto, 2019).

Pendidikan Kristen adalah tanggung jawab kita sebagai hamba Tuhan dan orang Kristen untuk memikirkan dengan serius, bagaimana menyelenggarakan pendidikan Kristen yang menolong membangun kehidupan anak-anak kita di atas batu karang yang teguh. Dalam pendidikan Kristen, juga diperlukan dalam pemberian reward dan consequences. Namun perlu diketahui bahwa dalam pemberian reward dan consequences, guru tetap menolong murid untuk mengenal Firman Tuhan sehingga dengan pemberian reward dan consequences murid tidak hanya mendapatkan sebuah hadiah dan hukuman saja, tetapi murid menjadi semakin termotivasi untuk belajar (Saerang, 2019). Selain itu, juga mendapatkan pengertian Firman Tuhan.

Dengan adanya uraian di atas, maka peneliti melakukan penelitian mengenai pengaruh pemberian reward dan consequences terhadap motivasi belajar murid. Sehingga agar guru menjadi lebih sadar dan peka mengenai pentingnya pemberian reward dan consequences. Dengan demikian, peneliti mengambil judul "Pengaruh Pemberian Reward dan Consequences Terhadap Motivasi Belajar Murid Kelas I dalam Kerangka Pendidikan Kristen".

Sekolah Dasar Kristen X Surabaya merupakan sekolah swasta yang melandaskan Alkitab dalam setiap kegiatan dalam sekolah. Selain itu, sekolah juga memberikan reward dan consequences yang positif untuk dapat menolong murid. Hal tersebut bertujuan agar murid dapat semakin mengenal Tuhan dan dapat bertumbuh melalui setiap pelajaran dan juga kegiatan yang ada. Harapannya, setiap guru dapat memberikan reward dan consequences sesuai dengan yang telah di lakukan oleh murid. Dengan demikian murid mendapatkan kesan yang menyenangkan dalam setiap pelajaran. Selain itu, agar murid juga dapat memunculkan motivasi belajar sendiri dari dalam dirinya.

Reward adalah menawarkan hadiah kepada anak didik yang melaksanakan berbagai perintah dan meninggalkan larangan (Tatang, 2012, p.97). Dari pendapat mengenai reward di atas, dapat disimpulkan bahwa reward adalah segala sesuatu penghargaan yang menyenangkan untuk diberikan kepada murid dengan tujuan murid selalu berbuat baik. Dengan bgeitu, fokus dari penghargaan tersebut bukanlah hasil yang akan dicapai oleh murid melainkan membentuk kemauan yang tinggi serta memiliki motivasi belajar.

Reward merupakan salah satu cara untuk menggerakkan atau menumbuhkan motivasi 
belajar murid (Oemar, 2013, p. 166). Dengan adanya pendapat mengenai reward di atas, dapat disimpulkan bahwa pemberian reward berupa hadiah sangat menolong murid dalam meningkatkan motivasi belajar.

Pemberian reward tidak semenamena dapat guru berikan kepada murid. Guru harus bisa memilih reward manakah yang cocok untuk diberikan kepada murid. Reward memiliki beberapa bentuk yakni materi dan non materi. Seperti yang disampaikan oleh Usman, penguatan atau reward adalah segala bentuk respon yang bersifat verbal atau nonverbal yang merupakan modifikasi dari tingkah laku guru terhadap tingkah laku murid yang bertujuan untuk memberikan informasi atau umpan balik si penerima atas perbuatannya sebagai dorongan ataupun koreksi. Dari pengertian tersebut keterampilan dasar penerapan reward terdiri dari beberapa komponen, antaranya:

a. Reward verbal

- Kata-kata: bagus, ya, tepat sekali, benar, good job, dan lain-lain.

- Kalimat: pekerjaan anda baik sekali, saya bangga dengan hasil kerjaan anda.

b. Reward non verbal

- Reward berupa gerak mimik dan badan. Contohnya: memberikan senyuman, acungan jari, tepuk tangan, dan lain-lain.

- Reward dengan mendekati. Guru dapat mendekati murid sebagai bentuk perhatian. Hal ini dapat dilaksanakan dengan cara guru berjalan menuju ke arah murid, guru berdiri di samping murid, guru duduk dekat murid, dan lainlain.

- Reward dengan sentuhan. Guru dapat memberikan persetujuan bahkan penghargaan kepada murid dengan cara menepuk pundak atau memberikan jabat tangan.

- Reward berupa simbol atau benda. Simbol tersebut bisa berupa surat, sertifikat, stiker. Sedangkan yang berupa benda hanya kartu bergambar, peralatan sekolah, dan lain-lain.

- Kegiatan yang membuat murid senang. Guru dapat memberikan tugas atau kegiatan yang disenangi oleh murid. Misalnya, seorang murid memiliki kegemaran membaca dan telah menyelesaikan tugas membacanya sehingga murid tersebut dapat diberi kebebasan lagi untuk membaca satu buku.

- Reward dengan memberikan penghormatan. Reward yang berupa penghormatan diumumkan dan ditampilkan di hadapan teman sekelasnya, teman-teman sekolah, atau mungkin juga dihadapan para orangtua murid.

- Reward dengan memberikan perhatian tak penuh. Reward tersebut diberikan kepada murid yang memberikan jawaban kurang sempurna. Misalnya, bila murid hanya memberikan jawaban sebagian, guru bisa menyatakan, "Ya jawabanmu sudah baik, tetapi masih perlu disempurnakan."

Adapun tujuan pemberian reward:

a. Membangkitkan dan merangsang belajar anak, lebih-lebih bagi anak yang kurang minat belajar dan lemah.

b. Mendorong anak agar selalu melakukan perbuatan yang lebih baik.

c. Menambahkan kegiatannya dan kegairahannya dalam belajar.

Consequences dapat diartikan menetapkan sanksi hukuman yang bersifat mendidik bagi semua murid yang melanggar peraturan, baik dalam keluarga, sekolah, maupun lingkungan sekitarnya (Tatang, 2012). Hukuman tersebut hendaknya menjadi jawaban atas pelanggaran murid. Sehingga dapat memperbaiki perilakunya. 
Hukuman dapat dikatakan juga sebagai penguatan namun bersifat negatif. Jika pendidik dapat memberikan hukuman secara tepat dan bijaksana, maka hukuman tersebut dapat menjadi sebah motivasi bagi siswa untuk berperilaku lebih baik. Oleh sebab itu, pemberian sebuah hukuman tidak dapat dilakukan dengan sembarangan. Dalam memberi consequences, sebaiknya guru tidak menggunakan hukuman badan dan jangan menggunakan hukuman perasaan, sebab hal tersebut dapat merusak hubungan kasih sayang pendidik dengan murid. Bahkan jika sering memberikan hukuman perasaan dan hukuman badan juga dapat mengganggu hubungan baik antara pendidik dan wali murid. Jangan sampai hukuman yang diberikan mengganggu psikologi murid di sekolah, misalnya malu atau takut ke sekolah karena diejek oleh teman. Alangkah baiknya jika pemberian consequences disesuaikan dengan tingkat perkembangan murid.

Adapun prinsip-prinsip pemberian consequences menurut pendidikan Kristen adalah sebagai berikut:

\section{a. Prinsip kasih}

Di dalam memberi consequences kepada murid, kasih merupakan prinsip yang paling mendasar. Dalam pemberian consequences perlu adanya kasih. Jika pemberian consequences tidak ada kasih, maka bisa jadi consequences tersebut tidak akan membuahkan hasil. Pemberian consequences tanpa adanya kasih yang sejati dapat mengarah kepada tindakan kekerasan. Jika memberi consequences tanpa dilandasi dengan kasih, maka murid dapat merasa kecawa bahkan merasa sedih saat mendapatkan consequences.

\section{b. Prinsip keadilan}

Memberi consequences harus disertai dengan keadilan. Setiawan berkata bahwa pemberian consequences haruslah adil kepada setiap anak (Setiawan, 2004). Dengan memberi consequences secara adil, maka murid tidak akan merasa bahwa dirinya dibeda-bedakan dengan temannya. Sehingga murid akan tetap bisa menerima dan menjalanken consequences.

c. Prinsip hukuman

Prinsip ini sebenarnya tidak baik diterapkan dalam sebuah pendidikan. Sebab jika dalam pemberian consequences guru memberikan hukuman, maka murid bisa merasa takut untuk belajar. James C. Dobson menentang pemberian consequences berupa pukulan sebab tangan merupakan perantara kasih. Jika pendidik memberikan hukuman berupa pukulan dapat memberikan kehancuran untuk setiap anak yang mendapat hukuman (Setiawan, 2000). Pernyataan ini dapat diartikan bahwa seorang pendidik harus dapat memilih consequences yang tepat untuk murid yang melanggar, sehingga murid tidak merasa hancur saat mendapatkan consequences.

Adapun tujuan dari pemberian consequences adalah untuk menimbulkan rasa tidak senang murid agar mereka tidak lagi berbuat negatif. Secara umum pemberian consequences menurut Hasanah dibagi menjadi dua bagian, yaitu:

\section{a. Alat pendidikan preventif}

Alat pendidikan yang memiliki sifat untuk mencegah. Sehingga dapat menjaga agar hal-hal yang dapat menghambat bahkan mengganggu proses belajar-mengajar dapat dihindari. Contoh: tata tertib, perintah, larangan, anjuran, dan lain-lain.

b. Alat pendidikan represi

Alat pendidikan yang bertujuan untuk menyadarkan kembali kepada hal-hal yang baik, benar, dan tertib. Contohnya: 
pemberitahuan, teguran peringatan, hukuman, dan lainlain.

Motivasi berasal dari kata "motif" yang diartikan sebagai upaya mendorong seseorang untuk melakukan sesuatu. Motif dapat dikatakan sebagai daya penggerak. Sehingga motivasi dapat diartikan sebagai daya penggerak yang telah menjadi aktif (Sardiman, 2012). Menurut Jeanne Ellis motivasi adalah sesuatu yang menghidupkan, mengarahkan, dan mempertahankan sebuah perilaku (Ormrod, 2008). Sebuah motivasi dapat membantu murid untuk menempatkan dirinya dalam suatu arah dan menjaga sikapnya.

Menurut Mc. Donald yang tertulis dalam buku dalam Tabrani (1992:100) menyatakan bahwa "motivation is an energy change within the person characterized by affective arousal and anticipatory goal reaction" yang artinya, motivasi adalah suatu perubahan energi dalam diri (pribadi) seseorang yang ditandai dengan timbulnya perasaan dan reaksi untuk dapat mencapai tujuan. Dari beberapa definisi tersebut dapat disimpulkan bahwa, motivasi adalah sebuah dorongan yang berada dalam diri seseorang yang menyebabkan seseorang untuk melakukan sesuatu sehingga mencapai tujuan tertentu.

Seringkali murid belum dapat memahami kegunaan dari belajar. Dengan adanya pemberian motivasi, murid dapat mengembangkan aktivitas dan inisiatif yang dapat mengarahkan dan memperlihatkan ketekunan dalam belajar.

Adapun fungsi dari motivasi belajar adalah sebagai berikut:

a. Dapat memberikan semangat dan mengaktifkan murid agar tetap berminat dan siaga. b. Memusatkan perhatian murid pada tugastugas tertentu yang berhubungan dengan pencapaian tujuan belajar.

c. Membantu memahami kebutuhan akan hasil jangka pendek dan jangka panjang.

Pendidikan Kristen adalah pendidikan yang bersumber dan berpusat pada Firman Allah yang tertulis dalam Perjanjian Lama dan Perjanjian Baru, berdasarkan Pancasila, berwawasan nasional dan global serta menekankan pada terwujudnya tinggi iman, tinggi pengabdian, tinggi disiplin, dan tinggi ilmu/teknologi dari peserta didik sebagai pribadi yang utuh dan dinamis.

Pendidikan Kristen tidak sama dengan pendidikan sekuler atau pendidikan religius lainnya. Ia berangkat dari dasar yang berbeda dan mempunyai tujuan yang berbeda pula. Dasarnya adalah Kebenaran Alkitab (Harris, 1997). Selain itu, Pendidikan Kristen juga dapat diartikan sebagai usaha menanamkan world-view atau sudut pandang dunia yang berpusat pada Tuhan serta bagaimana mereka berhubungan dengan individu Kristen lainnya (Taber \& Smalley, 1960).

Sekolah Kristen merupakan tempat yang paling efektif bagi murid untuk mendapatkan dan mencari kebenaran Alkitab melalui nilai-nilai yang ditanamkan. Namun masih banyak sekolah Kristen yang kurang tepat dalam menerapkan nilai-nilai Kekristenan baik dari aspek guru dalam mengajar atau pengelolaan sekolah. Namun ada juga sekolah yang sudah menerapkan pendidikan Kristen sesuai dengan kehendak Tuhan yaitu menerapkan CFRC (Creation, Fall, Redemption, and Consummation).

Pendidikan Kristen sendiri memiliki tujuan : (Majelis Pendidikan Kristen Indonesia, 2016)

1. Mengajarkan para murid ketetapan Hukum Allah

Musa mengajarkan kepada umat Allah bahwa mereka harus mencintai Tuhan dengan segenap hati, jiwa , dan segenap kekuatan mereka. Mereka haruslah 
memegang teguh ketetapan itu dalam hati mereka dan mengingatkan hal ini kepada keturunan mereka (Ulangan 6:57). Dengan kata lain pendidik Kristen harus membantu para murid mengerti apa yang di maksud dalam pengertian mencintai Tuhan dengan segenap hati, jiwa, akal budi, dan kekuatan, serta mengasihi sesama manusia seperti diri mereka sendiri. Mengajarkan ketetapan Hukum Allah sangat penting untuk dilakukan, karena Kristus adalah sumber dari segala aspek kehidupan manusia.Mengajarkan para murid untuk mempunyai hati yang takut akan Tuhan

Alkitab mengajarkan bahwa takut akan Tuhan adalah permulaan dari segala pengetahuan (Amsal 1: 2:15; 9:10) dan kunci untuk menikmati segala kekayaan yang Tuhan sediakan (Yesaya 33:5-6). Mereka yang takut akan Tuhan akan memiliki penghormatan dan pengetahuan akan keagungan, kesucian, dan kekuatanNya. Ini berarti jika sebagai seorang pendidik, kita harus dapat mengajarkan anak-anak untuk takut akan Tuhan. Dengan demikian pendidik dapat membuka pemikiran setiap murid kepada kekuatan dan keajaiban karya penciptaan-Nya (Mazmur 8 ; 139:14; dan Matius 16:26) sekaligus membawa mereka untuk menyadari akibat dari ketidakpercayaan mereka akan kuasa-Nya (Amsal 3:5-26).

2. Mengajarkan para murid untuk menjadi murid yang setia

Ketika Yesus bangkit dari kematian-Nya, Ia memberikan tugas kepada para muridNya untuk mewartakan kabar baik dan memperluas kerajaan-Nya di atas bumi ini (Matius 28:19-20). Para guru haruslah membantu murid untuk menjadi murid Tuhan Yesus yang setia dan bertanggung jawab dalam menjalankan misi Tuhan. Misi-Nya adalah untuk membuat perbedaan dalam setiap aspek kehidupan.

3. Mengajarkan para murid untuk mempergunakan talenta dalam melaksanakan tugas sebagai anggota tubuh Kristus

Paulus mengajarkan mengajarkan bahwa Tuhan telah memberikan orang-orang bertalenta pada gereja-Nya, termasuk para guru dan pendeta dengan tujuan yang jelas, yakni mempersiapkan orangorang pilihan-Nya untuk pekerjaan pelayanan. Dengan demikian kesatuan Tubuh Kristus dapat dibangun sampai mereka mencapai kedewasaan di dalam Kristus (Efesus 4:12-13).

4. Mengasuh para murid dalam pemeliharaan dan kedisiplinan Allah.

Paulus memberitahukan kepada orangtua bahwa mereka bertanggung jawab untuk memastikan anak-anak mereka dalam persiapan kehidupan yang hanya tertuju kepada Tuhan. Orangtua dan guru tidaklah boleh menyalahgunakan otoritas mereka kepada anak-anak mereka, melainkan mereka harus memastikan bahwa anak-anak mereka dibesarkan dalam pengenalan akan hidup di dalam Tuhan dan kepada jalan-Nya (Efesus 4:12-13).

Karakteristik pendidikan Kristen akan membantu sekolah Kristen memahami gambaran yang seharusnya dilakukan oleh sekolah Kristen. Dengan demikian sekolah Kristen dapat semakin banyak menjangkau jiwa-jiwa agar banyak murid dapat menjadi murid kerajaan Sorga.

Pada sekolah yang telah peneliti pilih, sekolah tersebut telah menerapkan pendidikan Kristen sehingga setiap pembelajaran yang ada, semua dilandaskan pada Firman Tuhan. Selain itu, pada setiap akhir pembelajaran, guru selalu 
mengimplementasikan pelajaran tersebut dengan CFRC (Creation, Fall, Redemption, and Consummation).

Sekolah Dasar Kristen X Surabaya juga menerapkan pemberian reward dan consequence. Setiap reward dan consequence yang diberikan oleh guru dapat menolong murid untuk mengingat kembali akan kebaikan Tuhan pada dirinya. Seperti contohnya jika murid mendapatkan reward karena dia dapat menjawab pertanyaan, maka guru tersebut akan menjawab "Good job, keren sekali. Kamu bisa menjawab seperti itu pasti kamu semalam belajar dan berdoa agar Tuhan menolong kamu dalam belajar ya?". Sebaliknya contoh pemberian consequence di saat murid jahil kepada temannya, maka guru akan berkata "Tuhan sedih loh melihat anaknya seperti itu, karena kamu sudah berbuat jahil dengan teman kamu. Waktu snack time kamu Ibu Guru kurangi ya."

Dengan pemberian reward dan consequences seperti itu, murid dapat memahami bahwa setiap apa yang dilakukan selalu mendapatkan pujian maupun hukuman. Tetapi pendidik perlu memberikan penjelasan mengenai pemberian reward dan consequences kepada murid. Sehingga dengan adanya penjelasan tersebut murid bisa lebih paham bahwa apapun yang dilakukannya akan membuahkan hasil secara positif maupun negatif.

\section{METODE PENELITIAN}

Penelitian dilakukan menggunakan pendekatan kuantitatif, yaitu untuk mengetahui pengaruh penggunaan reward dan consequences terhadap motivasi belajar murid kelas IV di Sekolah Dasar X Surabaya dalam kerangka pendidikan Kristen.

\section{Variabel Penelitian}

Variabel bebas penelitian ini adalah reward dan consequences sedangkan variabel terikatnya adalah motivasi belajar murid.

Variabel $\left(\mathrm{X}_{1}\right)$ : Reward

Variabel $\left(\mathrm{X}_{2}\right)$ : Consequences

Variabel (Y): Motivasi Belajar murid

\section{HASIL DAN PEMBAHASAN}

\section{Analisis Data}

Analisis regresi linier sederhana digunakan untuk melakukan uji pengaruh reward terhadap motivasi belajar dan consequences terhadap motivasi belajar. Sebaliknya regresi linier berganda digunakan untuk melakukan uji pengaruh reward dan consequences terhadap motivasi belajar secara bersamaan.

\section{Uji Pengaruh reward terhadap motivasi belajar}

Diketahui nilai $\mathrm{F}$ hitung sebesar 12,933 dan signifikansi adalah 0,001 <0,05. Sehingga Ho ditolak yang berarti regresi tersebut linier. Hasil dari tabel anova disimpulkan bahwa ada penolakan Ho dikarenakan tingkat signifikansi kurang dari 0,0 dan $\mathrm{F}$ hitung lebih besar dari $\mathrm{F}$ tabel 3,19. Besar pengaruh reward $\left(\mathrm{X}_{1}\right)$ terhadap motivasi belajar (Y) adalah 21,2\% , ini berarti78,8\% dipengaruhi oleh faktor lain. Adapun bentuk persamaan regresinya adalah $\mathrm{Y}=37,925+$ $0,432 \mathrm{X}_{1}$. Pada persamaan tersebut terlihat bahwa setiap variabel reward berubah naik satu satuan maka motivasi belajar bertambah sebesar 0,432 .

\section{Uji Pengaruh consequences terhadap motivasi belajar}

Diketahui bahwa nilai $\mathrm{F}$ hitung adalah sebesar 15,106 dan signifikansi adalah 0,000 $<0,05$. Sehingga Ho ditolak yang berarti regresi tersebut linier. Hasil dapat disimpulkan bahwa ada penolakan Ho dikarenakan tingkat signifikansi kurang dari 0,05 dan $\mathrm{F}$ hitung lebih besar dari $\mathrm{F}$ tabel 3,19 . Besar pengaruh consequences $\left(\mathrm{X}_{2}\right)$ 
terhadap motivasi belajar (Y) adalah $23,9 \%$, ini berarti $76,1 \%$ dipengaruhi oleh faktor lain. Adapun bentuk persamaan regresinya adalah $\mathrm{Y}=$ $30,596+0,488 \mathrm{X}_{2}$. Pada persamaan tersebut terlihat bahwa setiap variabel consequences berubah naik satu satuan maka motivasi belajar bertambah sebesar 0,488.

\section{Uji Pengaruh reward dan consequences terhadap motivasi belajar}

Diketahui bahwa nilai $\mathrm{F}$ hitung sebesar 10,207 dan signifikansi adalah $0,000<0,05$. Sehingga Ho ditolak yang berarti regresi tersebut linier. Kesimpulan hasil tersebut adalah terdapat penolakan Ho dikarenakan tingkat signifikansi kurang dari 0,05 dan $\mathrm{F}$ hitung lebih besar dari $\mathrm{F}$ tabel 3,19 . Besar pengaruh reward $\left(\mathrm{X}_{1}\right)$ dan consequences $\left(\mathrm{X}_{2}\right)$ terhadap motivasi belajar (Y) adalah berarti $30,3 \%$, ini berarti $69,7 \%$ dipengaruhi oleh faktor lain. Adapun bentuk persamaan regresinya adalah $\mathrm{Y}=$ $21,737+0,272 X_{1}+0,345 X_{2}$. Pada persamaan tersebut terlihat bahwa setiap variabel reward $\left(\mathrm{X}_{1}\right)$ dan consequences $\left(\mathrm{X}_{2}\right)$ berubah naik satu satuan maka motivasi belajar bertambah sebesar $0,272+0,345$.

Adapun diagram sebagai berikut:

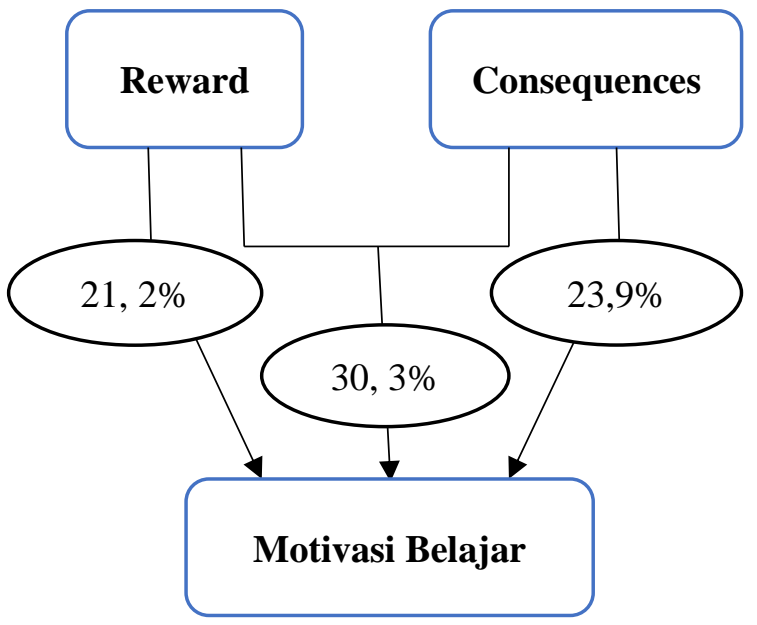

\section{Pembahasan}

Pemberian reward memiliki pengaruh yang positif terhadap motivasi belajar murid kelas 4 SD Kristen X Surabaya.

- Pegaruh pemberian reward terhadap motivasi belajar murid diperoleh thitung sebesar 3,596. Pemberian reward kepada murid menunjukkan adanya pengaruh terhadap motivasi belajar. Besar pengaruh pemberian reward terhadap motivasi belajar adalah 21,2\%

Hal ini berarti bahwa pemberian reward secara konsisten dan merata dapat memicu meningkatnya motivasi murid.

- Pengaruh pemberian consequences terhadap motivasi belajar murid diperoleh angka t hitung sebesar 3,887. APemberian consequences kepada murid menunjukkan ada pengaruh terhadap motivasi belajar. Besar pengaruh pemberian consequences terhadap motivasi belajar adalah 23,9\%. Hal ini berarti bahwa pemberian consequences secara konsisten dan merata dapat memicu meningkatnya motivasi murid.

- Pegaruh pemberian reward dan consequences secara bersama terhadap motivasi belajar murid diperoleh $\mathrm{t}$ hitung reward 2,068 < t hitung consequences 2,471 . Hal ini menunjukkan variabel yang paling dominan adalah consequences. Sedangkan besar pengaruh dari pemberian reward dan consequences terhadap motivasi belajar murid adalah $30,3 \%$.

Ada banyak macam dalam pemberian reward, jika pendidik dapat memberikan reward berupa kegiatan yang disukai oleh murid maka dapat meningkatkan motivasi belajar murid. Meskipun yang diberikan reward hanya satu murid. Sebab dengan adanya satu murid yang mendapatkan reward tersebut, maka ada kemungkinan jika murid yang lainnya dapat memicu kemampuannya untuk mendapatkan reward yang sama. Sehingga setiap murid dapat memiliki motivasi belajar yang tinggi. Sedangkan consequences juga memiliki macam-macamnya. Dalam pemberian 
consequences pendidik benar-benar harus memiliki hikmat yg benar dan tepat. Sebab jika pendidik salah memberikan consequences kepada murid, dapat membuat murid menjadi trauma atau membuat murid menjadi lebih malas.

Dengan demikian keterkaitan antara pengaruh pemberian reward dan consequences terhadap motivasi belajar murid semakin mempertegas pada konsep pendidikan. Pemberian reward merupakan salah satu cara yang dapat digunakan untuk meningkatkan motivasi belajar murid. Sebaliknya pemberian consequences jika digunakan dengan tepat dan bijak, juga dapat meningkatkan motivasi belajar murid. Apabila reward dan consequences diberikan secara tepat dan bijak kepada murid secara bersama-sama, maka motivasi belajar yang dimiliki oleh murid akan meningkat lebih besar daripada hanya menerapkan pemeberian reward saja atau consequences saja.

\section{KESIMPULAN}

Berdasarkan hasil penelitian yang telah dilakukan, maka disimpulkan sebagai berikut:

1. Terdapat pengaruh reward terhadap motivasi belajar yang signifikansi $0,001<0,05$, F hitung $=12,933>3,19$. Besar pengaruhnya adalah $21,2 \%$.

2. Terdapat pengaruh consequences terhadap motivasi belajar signifikansi $0,000<0,05, \mathrm{~F}$ hitung $=15,106>3,19$. Besar pengaruhnya adalah $23,9 \%$.

3. Terdapat pengaruh pemberian reward dan consequences terhadap motivasi belajar sebesar signifikansi $0,000<0,05$, F hitung $=10,207>3,19$. Besar pengaruhnya adalah $30,3 \%$.

\section{DAFTAR PUSTAKA}

Hamalik, Oemar. (2011). Proses Belajar Mengajar, Bandung:Bumi Aksara.

Jeanne, E., O. (2008). Psikologi Pendidikan. Jakarta: Erlangga.

Melinda, I. (2018). Pengaruh Reward dan Consequence Terhadap Motivasi Belajar Siswa Kelas IV A SDN Merak I pada Mata Pelajaran IPS. International Journal of Elementary Education, 2(2), 81-86. Retrieved from: https://scholar.google.com/scholar?hl $=$ en\&as_sdt $=0 \% 2 \mathrm{C} 5 \& \mathrm{q}=$ Pengaruh $+\mathrm{R}$ eward+dan+Consequence+Terhadap+ Motivasi+Belajar+Siswa\&btnG=

Noor, J. 2017. Metodologi penelitian: Skripsi, tesis, disertasi, \& karya ilmiah. Jakarta: Kencana.

Oemar, H. (2001). Kurikulum dan Pembelajaran.Jakarta : Bumi Aksara.

Puspitawati, S. (2016). Pengantar Interaksi Belajar Mengajar yang Efektif. Jakarta : Gunung Mulia.

Saserang, E. P. (2019). Penerapan reward dan consequence dalam pengelolaan kelas untuk membentuk kedisiplinan siswa (Doctoral dissertation, Universitas Pelita Harapan). Retrieved from:

https://scholar.google.co.id/scholar?q $=$ reward + dan + consequence + dalam $+p$ endidikan+kristen $\& \mathrm{hl}=\mathrm{en} \& \mathrm{as} \_\mathrm{sdt}=0$ \&as_vis= $1 \&$ oi $=$ scholart

Siregar, S. 2017. Metode pemilihan kuantitatif: Dilengkapi dengan perbandingan perhitungan manual \& SPSS. Jakarta: Kencana.

Tatang. (2012). Ilmu Pendidikan. Bandung: Pustaka Setia. 